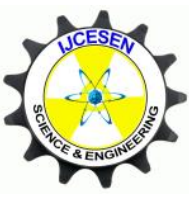

Copyright (C) IJCESEN
International Journal of Computational and

Experimental $\boldsymbol{S}$ cience and Engineering

(IJCESEN)

Vol. 3-No.1 (2017) pp. 11-20

http://iakkurt.dergipark.gov.tr/ijcesen

Research Article

\title{
Integrating Process Planning, WATC Weighted Scheduling, and WPPW Weighted Due-Date Assignment Using Pure and Hybrid Metaheuristics for Weighted Jobs
}

\section{Halil Ibrahim DEMIR ${ }^{1 *}$, Caner ERDEN², Ayhan DEMIRIZ ${ }^{3}$, Muharrem DUGENCÍ4 ${ }^{4}$, Ozer UYGUN ${ }^{5}$}

${ }^{1}$ Industrial Engineering, Sakarya University, Esentepe Campus, Sakarya, 54100, Turkey

${ }^{2}$ Industrial Engineering, Sakarya University, Esentepe Campus, Sakarya, 54100, Turkey

${ }^{3}$ Computer Engineering, Gebze Tecnical University, Gebze, Kocaeli, Turkey

${ }^{4}$ Industrial Engineering, Sakarya University, Esentepe Campus, Sakarya, 54100, Turkey

${ }^{5}$ Industrial Engineering, Karabük University, Karabük, Turkey

* Corresponding Author : hidemir@ sakarya.edu.tr

(First received 5 December 2016 and in final form 20 March 2017)

\# Presented in " $3^{\text {rd }}$ International Conference on Computational and Experimental Science and Engineering (ICCESEN-2016)"

\section{Keywords}

Process Planning,

Weighted Scheduling,

Weighted Due-Date Assignment,

Genetic Algorithm,

Evolutionary strategies,

Hybrid Metaheuristics,

Random Search

\begin{abstract}
Process planning, scheduling and due date assignment are three important manufacturing functions performed sequentially and separately. High interrelations between these functions forces us to consider integration. Here we studied integration of process planning, WATC scheduling and WPPW weighed due date assignment. At the literature due dates are assigned without taking into account of weights of each job but at this study we assigned closer due dates for more important customers. Thus we saved a lot at punishment function. Conventionally only tardiness is punished but according to JIT approach we should penalize both earliness and tardiness. Since nobody desire long due dates, at this study we penalized all of weighted earliness, tardiness and due date related costs. We used genetic algorithm, hybrid-genetic algorithm, evolutionary strategies, hybrid-evolutionary strategies, random search and ordinary solutions as solution techniques and we observed the superiority of search algorithms over random search and especially over ordinary solutions. We step by step integrated these functions and higher integration level is found better. Although there are numerous works on IPPS and SWDDA problems, there are only a few works on IPPSDDA problem.
\end{abstract}

\section{Introduction}

Conventionally three important manufacturing functions, process planning, scheduling and due date assignment are performed sequentially and separately. High relations among these three important functions requires us to handle them concurrently. Although these three functions are performed separately, recently there are numerous works on IPPS (Integrated process planning and scheduling) and hundreds of works on SWDDA (scheduling with due date assignment) and some works on IPPSDDA (Integrated process planning, scheduling and due date assignment).
As we sad there are a high interrelation among these three functions which makes integration a requirement. Inputs of upper stream functions become outputs to downstream functions. For instance, outputs of process planning function become inputs to dispatching function. If process plans are prepared separately and sequentially then process planners may select same desired machines continuously and may not select some unpreferred machines at all. This cause high workload at some machines and low workloads at some unpreferred machines. As a result, we get unbalanced shop floor loading. This reduce shop floor utilization and deteriorates global performance. 
Similarly, if due dates are determined independently from the other functions then we may give unnecessarily long due dates or unreasonably early due dates. If we give long due dates then we pay for high earliness and due date related costs. On the other hand, if we give unreasonably early due dates we pay for high tardiness related costs. If scheduling is performed independently then we may schedule jobs with earlier dates later or vice versa. At both case we pay for high tardiness or earliness related costs.

At the literature sometimes tardiness is punished, sometimes both earliness and tardiness is penalized, and sometimes number of tardy jobs is penalized. According to classical approach tardiness is penalized but according to JIT approach we should penalize both earliness and tardiness. Because no one prefers far due dates it is reasonable to reduce due date related costs too. Far due-date means price reduction, loos of good will, deterioration of the firm reputation and worse customer loss. For this reason, at this study we penalized all of weighted earliness, tardiness and due date related costs.

Process planning is defined according to Society of Manufacturing Engineers as the systematic determination of the methods by which a product is to be manufactured economically and competitively. Production scheduling is defined according to Zhang and Mallur as a resource allocator, which considers timing information while allocating resources to the tasks [1]. Gordon et al. [2] stated that the problems with due-date determination have received considerable attention in the last 15 years due to the introduction of new methods of inventory management such as just-in-time (JIT) concepts. In JIT systems jobs are to be completed neither too early nor too late which leads to the scheduling problems with both earliness and tardiness costs and assigning due dates.

If we look at the literature, we see that exact solutions are only possible for very small sized problems. It is because only scheduling sub problem belongs to NP-Hard class problems and integrated problems are even harder to solve. At this research we used genetic algorithm (GA) and evolutionary strategies (ES) as directed search, random search (RS) as undirected search and hybrid-genetic (RGA) and hybrid-evolutionary strategies (R-ES) as initially undirected and later directed search techniques while solving the integrated problem.

While applying pure and hybrid metaheuristics and random search we represented the problem as chromosomes. Each chromosome has $(n+2)$ genes where first two genes represent due date assignment rule and dispatching rule. Other genes represent currently selected routes of each job. While applying metaheuristics we used dominant genes approach. Since first two genes have very high impact on performance measure compared to the remaining genes we gave high probability for the first two genes to be selected for crossover and mutation operators.

One more important aspect of this research here is that we used weighted due date assignment. We assigned closer dates for more important jobs and scheduled these jobs earlier or vice versa. By doing this we saved a lot from the penalty costs of weighted earliness, tardiness and due date related costs.

We started from unintegrated combination where all three functions are disintegrated. Later we integrated three functions one by one and tested every intermediate combination. Finally, we integrated all three functions to prove full integration as the best combination. We compared metaheuristics with each other, with random search and with ordinary solutions (OS).

\section{Background and Related Researches}

Traditionally process planning, scheduling and due date assignment are performed sequentially and separately. Although there are plenty of works on IPPS and on SWDDA, there are only a few works on IPPSDDA. Demir and Taskin [3] worked on IPPSDDA in a Ph.D thesis and later Ceven and Demir [4] studied benefit of integrating due date assignment with IPPS problems in an M.S. Thesis. Later Demir et al [5]continued to study IPPSDDA problem [6].

If we look at integrated solutions of these three functions, we can find numerous works on sub integrations. There are many works on IPPS problem. For a good review on IPPS problem it is better to see Tan and Khosnevis [7]. Also Li et al [8] and Phanden et al [9] can be read as IPPS review.

According to the literature, since scheduling is NPHard class problem integrated problem is even harder to solve. That's why in solution of IPPS problem some heuristics, metaheuristics are used. Exact solutions are only possible for very small problems and as problems get bigger it becomes practically not possible to find exact solutions to the problem. In this case we need to find a good solution instead of the best solution. Since integrated problems are even more complex, researchers decomposed the IPPS problem into loading and 
scheduling sub problem. Demir and $\mathrm{Wu}$ decomposed problem into loading and scheduling sub problems and solved the IPPS problem in an M.S. Thesis. While solving integrated problem some researchers applied evolutionary algorithms, genetic algorithms or agent based solutions to the problem [10].

Since IPPSDDA problem is even more complex, we used genetic search and random search while solving the problem.

As we mentioned, there are numerous works on IPPS problem and Khosnevis and Chen [11], Hutchinson et al [12], Chen and Khoshnevis [13], Zhang and Mallur [1], Brandimarte [14], Kim and Egbelu [15], Morad and Zalzala [16] are some examples to earlier IPPS researches.

If we give a list of some recent researches on IPPS, Tan and Khoshnevis [7], Kim et al [17], Usher [18], Lim and Zhang [19], Tan and Khoshnevis [20], Kumar and Rajotia [21], Moon et al [22], Li et al [17], Leung et al [23], Phanden et al [8] are more recent examples.

Another important research topic is SWDDA problem. This problem is also more complex compared to scheduling problem and here we assign better due dates and schedule jobs simultaneously that gives better performance measure. For a good review it is better to see Gordon et al [2].

Due dates can be determined as endogenous or exogenous. If dates are determined as exogenous then firm has no control over the due dates. On the other hand, if dates are determined endogenous then firm try to find better due dates that give better global performance.

Some works are on SMSWDDA (Single machine scheduling with due date assignment) and some works are on MMSWDDA (multiple machine scheduling with due date assignment). At the former case jobs are scheduled with due date assignment before a single machine. At the latter case some jobs are scheduled with due date assignment before some machines. At this research we have $m$ machines and $\mathrm{n}$ jobs to be scheduled with due date assignment before these $m$ machines.

Some researches assign common due date for the jobs to be scheduled. This may be possible for the jobs waiting to be assembled together. But in this research we assigned separate due dates for each job.

Panwalker [24], Gordon and Kubiak [25], Biskup and Jahnke [26], Cheng et al. [27], Ventura and
Radhakrishan [28], Cheng et al [29], Wang [30], Lin et al [31], Xia et al [32], Gordon and Strusevich [33], and $\mathrm{Li}$ et al. [34] are some examples SMSWDDA problem.

On the other hand, following works are on MMWDDA problem. Adamapolous and Pappis [35], Cheng and Kovalyov [36], and Lauff and Werner [37] are some examples to this kind of problems.

At the literature, conventionally tardiness is penalized. But according to JIT both earliness and tardiness should be punished. On the other hand, in this study we penalized all weighted earliness, tardiness and due date related costs. Since nobody wants late due dates, we should penalize due date related costs. Long due dates cause customer ill will, price reduction and even customer loss. In JIT environment and in reality earliness is also undesired. Earliness cause unnecessarily stock keeping, spoilage and inventory holding costs. Similarly, due date related costs, tardiness is also undesired. Tardiness means that we could not keep our promises. Nobody wants tardiness and tardiness damage firm reputation, cause loss of customer good will, price reduction and worse we may have lost customer.

\section{Definition of the Problem}

If we define the problem in general; Process planning, scheduling and due date assignment three important manufacturing functions performed separately and with this research we tried to solve integrated process planning, WATC (weighted apparent tardiness cost) scheduling and WPPW (Weighted process plus wait) due date assignment. We used WATC as dispatching rule and WPPW as due date assignment rule. We gave closer dates to important customers by using WPPW and scheduled important customers earlier by using WATC rule.

We used some pure and hybrid search metaheuristics as solution techniques and we used chromosomes to represent the problem.

Specifically, we studied four shop floors with the characteristics summarized at Table 1 . We have $n$ jobs to be scheduled and due dates are to be assigned, we have $m$ machines and $r$ routes of each job. Each jobs are to be assigned unique, separate due dates.

To be example if we explain shop floor 1, we have 25 jobs to be scheduled and due dates assigned, each job has 5 alternative routes and we have 5 machines at the shop floor. Processing times assumes integer 
values practically in between 1 and 30 according to a normal distribution with mean 12 and standard deviation 6.

Table 1. Shop Floors

\begin{tabular}{|l|c|c|c|c|}
\hline Shop floor & $\begin{array}{c}\text { Shop floor } \\
1\end{array}$ & $\begin{array}{c}\text { Shop floor } \\
2\end{array}$ & $\begin{array}{c}\text { Shop floor } \\
3\end{array}$ & $\begin{array}{c}\text { Shop floor } \\
4\end{array}$ \\
\hline $\begin{array}{l}\text { \# of } \\
\text { machines }\end{array}$ & 5 & 15 & 25 & 35 \\
\hline \# of Jobs & 25 & 75 & 125 & 175 \\
\hline \# of Routes & 5 & 5 & 3 & 3 \\
\hline $\begin{array}{l}\text { Processing } \\
\text { Times }\end{array}$ & $\begin{array}{l}\lfloor(12+\mathrm{z} \\
* 6)\rfloor\end{array}$ & $\begin{array}{l}\mathrm{L}(12+\mathrm{z} \\
* 6)\rfloor\end{array}$ & $\begin{array}{l}\mathrm{L}(12+\mathrm{z} \\
* 6)\rfloor\end{array}$ & $\begin{array}{l}\mathrm{L}(12+\mathrm{z} \\
* 6)\rfloor\end{array}$ \\
\hline $\begin{array}{l}\text { \# of op. per } \\
\text { job }\end{array}$ & 10 & 10 & 10 & 10 \\
\hline
\end{tabular}

As a beginning we tested fully unintegrated version and we obtained very poor results. Later we integrated WATC scheduling with process plan selection and obtained substantial improvement. After that we integrated process plan selection with WPPW due date assignment but jobs are scheduled in random order. Although with this integration high improvement is obtained but SIRO (Service in random order) rule strictly deteriorated overall performance back. Finally, we integrated all three functions fully and we obtained best results.

We assumed one day as 480 working minutes. If we have one shift than it makes 480 minutes. As a punishment function we penalized weighted earliness, tardiness and due date related costs. For earliness and tardiness, we used both variable and fixed costs.

Every terms of punishment functions are summarized below where $\operatorname{PD}(\mathrm{j})$ is penalty of duedate of job j, PE(j) is penalty of earliness of job j, PT(j) is penalty of tardiness of job j, Penalty of a job is Penalty(j) and Total penalty of all jobs are as follows;

$$
\begin{aligned}
& P D(j)=\text { weight }(j) * 8 *\left(\frac{D}{480}\right) \\
& P E(j)=\text { weight }(j) *\left(5+4 *\left(\frac{E}{480}\right)\right) \\
& P T(j)=\text { weight }(j) *\left(10+12 *\left(\frac{T}{480}\right)\right) \\
& \text { Penalty }(j)=P D(j)+P E(j)+P T(j) \\
& \text { Total Penalty }=\sum_{j}^{\text {Penalty }(j)}
\end{aligned}
$$

\section{Searches Used}

Here we used some pure and mixed search techniques and compared them with each other and with ordinary solutions to observe how ordinary solutions are poor compared to search results and how search techniques outperforms random search.

Because integrated problem is NP-Hard problem we used genetic and evolutionary based search techniques and random search metaheuristics in solution and we represented problem as chromosomes which is illustrated at Figure 1 below.

If we explain the solution techniques from the poorest we can give following definitions;

Ordinary Solution: This is the poorest solution and it is the solution of initial chromosome where no iterations are performed.

Ordinary solution for each integration level and for every shop floors are summarized at the Table 5, and Figures 2,3,4,5.

Random Search (R): Here we used three populations as big as in genetic search. At every iteration we randomly produce 8 chromosomes instead of crossover population and we randomly produce 5 chromosomes instead of mutation population. We have a population with size 10 from the previous main population. Out of these three populations with size 23 chromosomes we select best 10 chromosomes as the new main population and we complete one random iteration. We apply 200, 100 and 50 random iterations for the shop floors respectively. CPU times to complete these many random iterations are summarized at Table $\mathrm{X}$. Random search results are summarized again at Table 5 and illustrated at Figure 2,3,4,5.

Evolutionary Strategies (ES): At the beginning of 1960s evolutionary strategies is developed in Germany. Two students at Berlin Technical University, Ingo Rechenberg and Hans-Paul Schwefel were working on optimum flow pattern and when they found that they need to make numerous experiments then they decided to continue the experiments where parameters to define flow pattern are determined randomly. Thus evolutionary strategies was born. The difference between evolutionary strategies and genetic algorithms is the operators used. ES uses only mutation operator where GA use both mutation and crossover operators. Here at every iteration in all search techniques same amount of new offsprings are used. At ES algorithm at every iteration we produced 13 new offsprings by using mutation operator. [36][37]

Hybrid Evolutionary Strategies (R-ES): At Hybrid-ES both random search and ES algorithm are applied. Initial $10 \%$ iterations were random and 
remaining 90\% iterations were ES iterations. Hybrid search is used because random searches at the beginning are marginally very useful. For example if we produce a number in between 0 and 1 then expected value is 0,5 . So marginal benefit is 0,5 . Now if we produce two numbers and take maximum then expected value is $2 / 3$ and now this time marginal benefit reduces to 0,167 . Later if we produce three random numbers and take maximum of these numbers, then expected value becomes 3/4 and marginal benefit this time reduces to 0,083 . As it can be seen from marginal benefits, early random iterations are very beneficial to scan solution space better. Here it is vitally important to determine random search percentages to get best hybrid search and we applied 10\% random iterations at the beginning.

Genetic Search (GA): At this technique we used genetic operators to produce new offsprings instead of randomly produced chromosomes. While producing new offsprings we get use of earlier solutions with the probability determined according to the performance measure. That is why this search is called directed search and it uses earlier best solutions but at the random search always we produce brand new solutions randomly and we don't use earlier best solutions and that is why this search is undirected search. Although marginal benefits of earlier iterations of random search is very high, Marginal benefits reduce sharply as iteration goes on and genetic search becomes superior over random search.

We have three populations with sizes 10,8 and 5 respectively. At every step we use main population and according to performance measure we give probabilities for main population chromosomes to be selected for crossover or mutation operators. By using 4 pairs of chromosomes we produce new 4 pairs of chromosomes for crossover population. From 5 chromosomes selected from main population by applying mutation operators we produce new 5 chromosomes. From previous main population and newly produced crossover and mutation populations we select best ten chromosomes for the new main population and complete one genetic iteration. We apply 200, 150,100 and 50 genetic iterations for the shop floors respectively and required CPU times are given at Table 5. Genetic search results are given at Table 5 and illustrated at Figure 2,3,4,5 respectively.

Hybrid Genetic Search (R-GA): As we explained above random search is very useful just at the very beginning to scan solution space better and marginal benefit of random search is very high at the beginning and sharply reduces as iteration goes on.
Important thing here is to determine random search percentages and we applied 10\% random iterations and continued with genetic iterations.

For every pure and hybrid searches used R and ES or GA iteration numbers are summarized at Table 2 below.

Table 2. Iteration Numbers For Pure and Hybrid Searches

\begin{tabular}{|l|l|l|l|l|l|l|l|}
\hline & ES & \multicolumn{2}{|l|}{ R-ES Hybrid } & RS & GA & \multicolumn{2}{l|}{$\begin{array}{l}\text { R-GA } \\
\text { Hybrid }\end{array}$} \\
\hline $\begin{array}{l}\text { Shop } \\
\text { Floor }\end{array}$ & $\begin{array}{l}\text { ES } \\
\text { Iter\# }\end{array}$ & $\begin{array}{l}\text { Random } \\
\text { Iter\# }\end{array}$ & $\begin{array}{l}\text { ES } \\
\text { Iter\# }\end{array}$ & $\begin{array}{l}\text { Random } \\
\text { Iter\# }\end{array}$ & $\begin{array}{l}\text { GA } \\
\text { Iter\# }\end{array}$ & $\begin{array}{l}\text { Random } \\
\text { Iter\# }\end{array}$ & $\begin{array}{l}\text { GA } \\
\text { Iter } \\
\#\end{array}$ \\
\hline 1 & 200 & 20 & 180 & 200 & 200 & 20 & 180 \\
\hline 2 & 150 & 15 & 135 & 150 & 150 & 15 & 135 \\
\hline 3 & 100 & 10 & 90 & 100 & 100 & 10 & 90 \\
\hline 4 & 50 & 5 & 45 & 50 & 50 & 5 & 45 \\
\hline
\end{tabular}

We used chromosomes while representing and solving the problem. We have $(n+2)$ genes and first two gens represent due-date assignment and scheduling rule genes and remaining genes are for selected routes of jobs. A sample chromosome is represented at Figure 1.

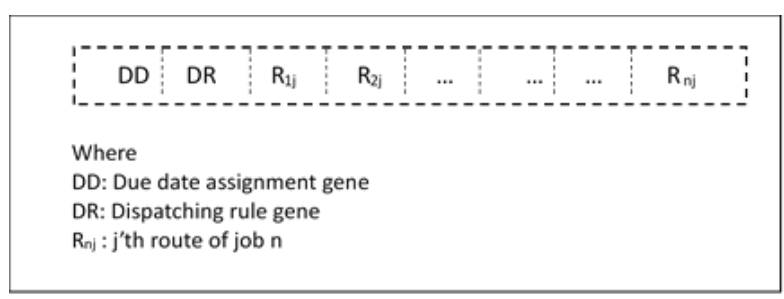

Figure 1. Sample Chromosome

Since first two genes much higher effects on performance measure compared to the rest of the genes we gave much higher probability for the first two genes to be selected for crossover and mutation operators.

First gene is the due date assignment rules gene. We used mainly two rules for due date assignment and with different multipliers and constants we used 10 due date assignment rules which are summarized at Table 3 and Appendix A.

Table 3. Due-Date Assignment Rules

\begin{tabular}{|l|l|l|l|}
\hline Method & Multiplier & Constant & Rule No \\
\hline WPPW & $\mathrm{k}_{\mathrm{x}}=1,2,3$ & $\mathrm{q}_{\mathrm{x}}$ & $1,2,3,4,5,6,7,8,9$ \\
\hline RDM & & & 10 \\
\hline
\end{tabular}


Second gene is about scheduling rules. We used mainly two rules while dispatching the jobs. Scheduling rules are WATC and SIRO rules. With the multipliers we used totally 4 rules while dispatching the jobs.

Table 4. Dispatching Rules

\begin{tabular}{|l|l|l|}
\hline Method & Multiplier & Rule No \\
\hline WATC & $\mathrm{k}_{\mathrm{x}}=1,2,3$ & $1,2,3$ \\
\hline SIRO & & 4 \\
\hline
\end{tabular}

\section{Solution Combinations}

At this research we tested different integration levels with some pure and hybrid search techniques and compared search results with ordinary solutions. Totally we compared twenty four combinations, four of them ordinary solutions for each of the integration levels, four of them were for each search techniques for every integration levels. Below every integration levels for every search techniques are explained in detail.

SIRO-RDM(OS,RS,ES,R-ES,GA,R-GA): This is the unintegrated version and due dates are assigned randomly and jobs are scheduled in random order. All of the search techniques are applied at this level and results are summarized at Table 5.

\section{WATC-RDM(OS,RS,ES,R-ES,GA,R-GA):Here} we integrated WATC rule with process plan selection but due dates are still determined randomly. Here again every search techniques are applied and results are summarized at Table 5. This level of integration provided substantial improvement in overall performance measure.

\section{SIRO-WPPW(OS,RS,ES,R-ES,GA,R-GA):This}

time we integrated WPPW due date assignment rule with process planning but jobs are scheduled in random order. Even though we provided substantial improvements in performance measure SIRO rule strictly deteriorates the overall performance back.

WATC-WPPW(OS,RS,ES,R-ES,GA,R-GA):This is the highest level of integration where process plan selection is integrated with WATC weighted scheduling and WPPW weighted due date assignment. This level was found the best level in terms of performance measure. Results are summarized at Table 5 and Figures 2,3,4,5.

Twenty four combinations above are compared. Every search techniques and random search are compared with each other and with ordinary solutions. Results are summarized at the next section VI and interpreted at the conclusion section.

\section{Experiments}

We coded the program using $\mathrm{C}++$ programming language and used Borland $\mathrm{C}++5.02$ compiler. We run the program on a desktop with a processor intel i5- 4590 with $3,3 \mathrm{GHz}$ and 8 GB Ram. Required CPU times are recorded and summarized at Table 5.

As a due date assignment rule we used one of 10 different values and as a dispatching rule we used one of 4 different values. Every chromosome consists of $(n+2)$ genes where $n$ is the number of the jobs.

We tested four shop floors and features of the shop floors are given at Table 1. We applied predetermined number of pure or hybrid iterations to the shop floors and combinations of these iterations are summarized at Table 2 .

We started by solving unintegrated combinations where we solved SIRO-RDM(OS,RS,ES,RES,GA,R-GA) combinations. After that we integrated WATC scheduling with process plan selection but due dates are still determined randomly. At this step we solved WATCRDM(OS,RS,ES,R-ES,GA,R-GA) combinations. Later we integrated due date assignment with process plan selection but this time jobs are scheduled in random order. We used WPPW as due date determination rule and we tested SIROWPPW(OS,RS,ES,R-ES,GA,R-GA) combinations. Finally, we integrated three functions and process plan selection is integrated with WATC dispatching rule and WPPW due date determination rule and WATC-WPPW(OS,RS,ES,R-ES,GA,R-GA) combinations are tested. Full integration level was the ultimate goal of this study.

First shop floor was the smallest shop floor with 25 jobs and 5 machines. We have 5 alternative routes and $200 \mathrm{RS}, \mathrm{ES}, \mathrm{R}-\mathrm{ES}, \mathrm{GA}$ and R-GA iterations are applied for this shop floor. CPU times are recorded for this shop floor and listed at Table 5. It took approximately 20 to 40 seconds to complete 200 iterations. Results of small shop floor are summarized at Table 5 and illustrated at Figure 2. Full integration level with R-ES search technique is found the best combination. Search technique results were near and much better compared to the ordinary solution.

Second shop floor was with 75 jobs and 15 machines. Each job has 5 alternative routes and we 
applied 150 pure and hybrid iterations to solve the problem. CPU times are summarized at Table 5. CPU times were approximately in between 200 to 400 seconds. Again full integration with genetic search was the best combination. Genetic search outperformed other searches and ordinary solution was the poorest. Results of second shop floor is summarized at Table 5 and illustrated at Figure 3.

Third shop floor was with 125 jobs and 25 machines. In order to save from CPU times and to reduce required memory we used 3 alternative routes and we applied 100 pure and hybrid iterations while solving the problem. It took approximately 200 to 600 seconds to complete 100 iterations. Here similar results are obtained. R-GA outperformed other searches and ordinary solutions were the poorest. Full integration level is found the best level of integration. Results are tabulated at Table 5 and illustrated at Figure 4.
Final shop floor was with 175 jobs and 35 machines. Each job has 3 alternative routes and we applied 50 pure and hybrid searches. It took approximately 200 to 500 seconds to complete 50 iterations. Here similar results are obtained and R-GA outperformed other techniques and ordinary solutions found the poorest. Full integration level is found as the best level of integration as expected. Results are tabulated at Table 5 and illustrated at Figure 5.

\section{Conclusions}

We studied integration of process planning with WATC weighted scheduling and WPPW weighted due date assignment. We didn't integrate three functions at first. We tested unintegrated combinations and later step by step we integrated each function with each other. We tried to observe intermediate integrations are helpful and full

Table 5. Experimental Results

\begin{tabular}{|c|c|c|c|c|c|c|c|c|c|c|c|c|c|c|c|c|c|}
\hline \multirow{2}{*}{$\begin{array}{l}\text { Level of } \\
\text { Integration } \\
\text { (Combination) }\end{array}$} & \multirow[b]{2}{*}{ Approaches } & \multicolumn{4}{|c|}{ Shop Floor 1} & \multicolumn{4}{|c|}{ Shop Floor 2} & \multicolumn{4}{|c|}{ Shop Floor 3} & \multicolumn{4}{|c|}{ Shop Floor 4} \\
\hline & & Best & Avg. & Worst & CPU & Best & Avg. & Worst & CPU & Best & Avg. & Worst & $\mathrm{CPU}$ & Best & Avg. & Worst & CPU \\
\hline \multirow{6}{*}{ SIRO-RDM } & Ordinary & 292,6 & 292,6 & 292,6 & 20,0 & 906,5 & 906,5 & 906,5 & 250,0 & 1412,8 & 1412,8 & 1412,8 & 650,0 & 2019,7 & 2019,7 & 2019,7 & 290,0 \\
\hline & ES & 269,0 & 272,1 & 274,5 & 16,8 & 824,2 & 835,7 & 841,1 & 212,6 & 862,0 & 864,5 & 865,8 & 624,9 & 1843,3 & 1861,5 & 1870,1 & 269,9 \\
\hline & Hybrid ES & 248,0 & 252,3 & 254,7 & 19,9 & 827,1 & 835,0 & 839,5 & 248,6 & 1322,3 & 1324,8 & 1327,5 & 265,4 & 1860,6 & 1874,5 & 1885,0 & 281,5 \\
\hline & \begin{tabular}{|l|}
$\mathrm{GA}$ \\
\end{tabular} & 249,3 & 256,0 & 259,4 & 16,3 & 803,0 & 815,7 & 819,9 & 201,9 & 1291,0 & 1300,7 & 1305,8 & 256,6 & 1846,2 & 1856,7 & 1864,0 & 268,0 \\
\hline & Hybrid GA & 264,8 & 269,1 & 271,7 & 16,7 & 814,0 & 818,4 & 822,0 & 204,8 & 1305,9 & 1312,2 & 1315,6 & 260,5 & 1856,6 & 1869,1 & 1878,2 & 270,3 \\
\hline & Random & 267,6 & 273,2 & 274,8 & 18,0 & 853,0 & 864,2 & 869,6 & 211,1 & 1355,0 & 1371,7 & 1378,2 & 274,9 & 1907,5 & 1925,3 & 1934,1 & 278,7 \\
\hline \multirow{6}{*}{ WATC-RDM } & Ordinary & 241,0 & 241,0 & 241,0 & 35,0 & 717,2 & 717,2 & 717,2 & 410,0 & 1199,8 & 1199,8 & 1199,8 & 512,0 & 1722,9 & 1722,9 & 1722,9 & 530,0 \\
\hline & \begin{tabular}{|l|}
$\mathrm{ES}$ \\
\end{tabular} & 198,8 & 202,0 & 202,7 & 33,0 & 643,8 & 649,8 & 654,1 & 373,1 & 1081,9 & 1099,9 & 1107,4 & 479,9 & 1595,8 & 1600,9 & 1604,5 & 522,2 \\
\hline & Hybrid ES & 203,5 & 206,1 & 208,6 & 34,2 & 621,4 & 632,6 & 637,3 & 370,2 & 1110,6 & 1115,5 & 1119,0 & 497,0 & 1595,8 & 1614,0 & 1623,3 & 508,4 \\
\hline & GA & 201,8 & 204,7 & 206,4 & 33,1 & 633,6 & 643,4 & 647,7 & 365,0 & 1080,8 & 1089,9 & 1095,9 & 459,5 & 1523,0 & 1538,5 & 1549,2 & 497,9 \\
\hline & Hybrid GA & 201,8 & 204,7 & 206,4 & 33,1 & 636,6 & 643,6 & 648,0 & 401,2 & 1100,5 & 1102,7 & 1105,6 & 464,4 & 1573,8 & 1580,0 & 1583,8 & 508,2 \\
\hline & Random & 217,6 & 222,9 & 224,7 & 34,3 & 693,8 & 699,3 & 703,1 & 230,0 & 1162,3 & 1173,5 & 1179,1 & 510,8 & 1634,0 & 1658,9 & 1667,5 & 523,6 \\
\hline \multirow{6}{*}{ SIRO-WPPW } & Ordinary & 306,7 & 306,7 & 306,7 & 21,0 & 938,8 & 938,8 & 938,8 & 228,0 & 1468,3 & 1468,3 & 1468,3 & 290,0 & 2120,9 & 2120,9 & 2120,9 & 310,0 \\
\hline & ES & 254,7 & 257,9 & 261,8 & 20,0 & 831,2 & 843,1 & 848,9 & 225,5 & 1306,9 & 1317,6 & 1324,0 & 289,8 & 1856,2 & 1873,0 & 1883,7 & 299,9 \\
\hline & Hybrid ES & 248,5 & 255,3 & 259,0 & 20,5 & 829,9 & 840,0 & 847,1 & 217,3 & 1312,9 & 1342,9 & 1352,2 & 287,6 & 1859,7 & 1881,5 & 1892,0 & 294,3 \\
\hline & GA & 244,0 & 248,1 & 250,1 & 19,3 & 821,3 & 824,4 & 827,1 & 221,3 & 1300,8 & 1309,9 & 1315,2 & 286,1 & 1818,7 & 1833,6 & 1842,8 & 292,3 \\
\hline & Hybrid GA & 250,1 & 253,1 & 255,5 & 20,5 & 805,2 & 809,0 & 812,4 & 221,1 & 1290,5 & 1296,2 & 1303,0 & 278,8 & 1808,9 & 1832,5 & 1842,7 & 303,3 \\
\hline & Random & 266,4 & 273,6 & 276,5 & 20,1 & 836,2 & 857,2 & 862,9 & 226,2 & 1336,4 & 1352,8 & 1359,3 & 284,9 & 1818,7 & 1833,6 & 1842,8 & 292,3 \\
\hline \multirow{6}{*}{ WATC-WPPW } & Ordinary & 233,2 & 233,2 & 233,2 & 39,0 & 732,0 & 732,0 & 732,0 & 420,0 & 1153,1 & 1153,1 & 1153,1 & 530,0 & 1787,5 & 1787,5 & 1787,5 & 580,0 \\
\hline & ES & 182,1 & 183,3 & 183,9 & 36,7 & 574,2 & 575,5 & 576,4 & 410,0 & 877,0 & 883,7 & 887,7 & 510,2 & 1331,5 & 1352,5 & 1365,3 & 562,2 \\
\hline & Hybrid ES & 179,4 & 180,4 & 181,0 & 36,7 & 570,5 & 571,7 & 573,2 & 409,5 & 886,8 & 903,7 & 910,9 & 510,3 & 1321,2 & 1334,4 & 1343,0 & 562,3 \\
\hline & GA & 181,7 & 182,1 & 182,4 & 37,3 & 568,2 & 569,3 & 570,8 & 412,3 & 866,3 & 872,7 & 875,6 & 517,8 & 1303,9 & 1307,9 & 1311,9 & 556,0 \\
\hline & Hybrid GA & 183,4 & 184,1 & 184,3 & 37,8 & 573,7 & 574,4 & 574,8 & 416,0 & 850,6 & 854,4 & 857,2 & 514,3 & 1275,7 & 1283,0 & 1286,2 & 549,3 \\
\hline & Random & 183,9 & 190,6 & 192,4 & 38,0 & 580,3 & 589,0 & 592,4 & 419,4 & 909,0 & 925,3 & 936,6 & 526,4 & 1304,8 & 1333,8 & 1348,5 & 569,8 \\
\hline
\end{tabular}

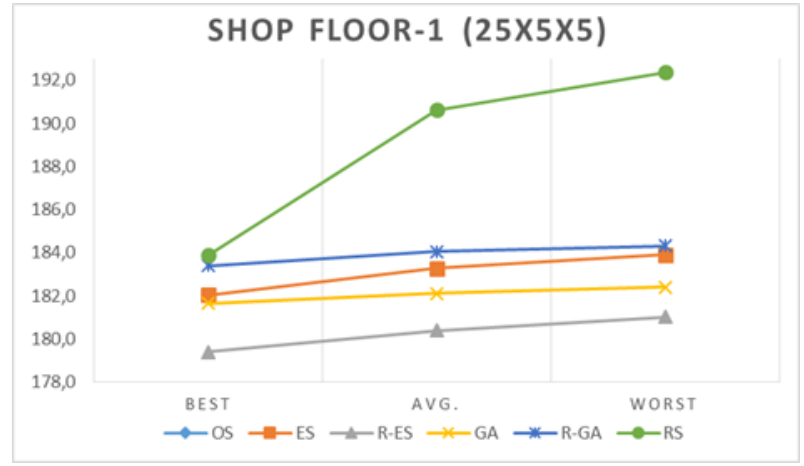

Figure 2. Shop Floor-1 (25x5x5) Results

\section{SHOP FLOOR-2 (75X15X5)}

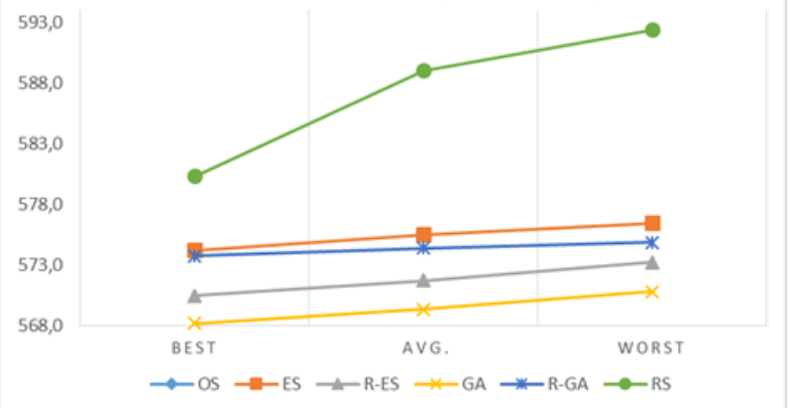

Figure 3. Shop Floor-1 (25x5x5) Results 


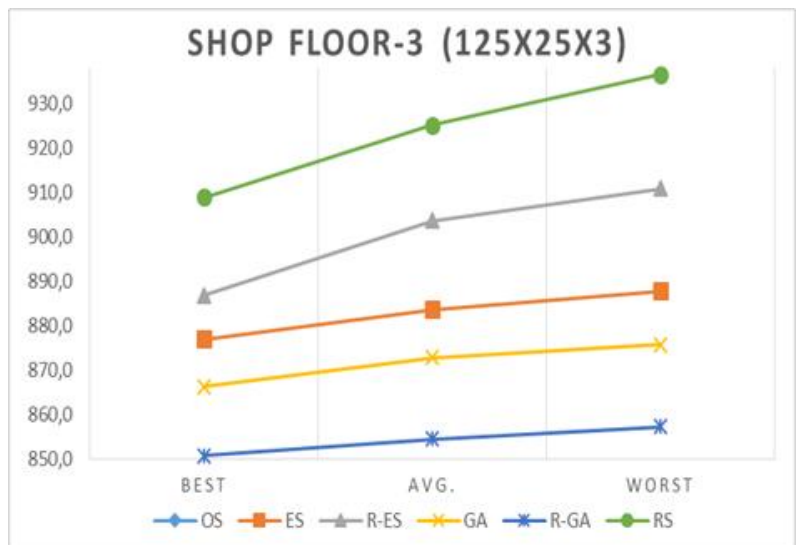

Figure 4. Shop Floor-3 (125x25x3) Results

integrated version as the best combinations. If we perform each function separately and sequentially then every function tries to reach local optima and don't care about global optima. Because only scheduling problem is NP-Hard problem and integrated versions are even harder to solve. For this reason, some metaheuristics such as ES, R-ES, GA, R-GA and RS search techniques are applied in solution.

Although there are hundreds of works on IPPS and SWDDA problems, there are only a few works on IPPSDDA problem. Here we integrated due date assignment to IPPS problem and we increased integration level. Due dates are determined internally and externally. For external due date assignment, we used RDM (Random) due date assignment technique and for the internal weighted due date assignment we used WPPW due date assignment techniques. By taking into accounts of weights of each customer we provided substantial improvements in global performance which is sum of weighted earliness, tardiness and due date related costs. Although traditionally only tardiness is penalized, according to JIT approach we should penalize both earliness and tardiness. Furthermore, at this study we also penalized due date related costs. Since no customer wants long due dates it was reasonable to penalize all of weighted earliness, tardiness and due date related costs.

At the very beginning we tested fully unintegrated versions to see how poor is the unintegrated versions and to observe benefit of level of integration.

As a next step we integrated WATC scheduling with process planning but due dates are determined randomly. We observed substantial improvements by this integration.

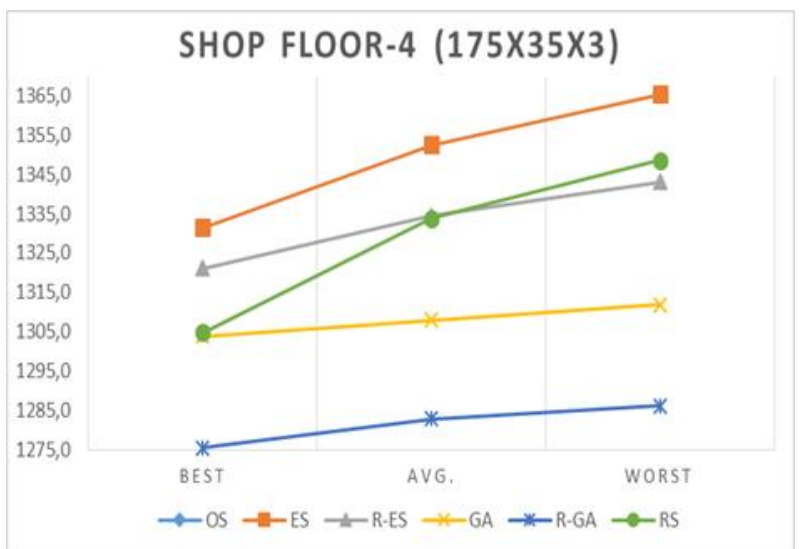

Figure 5. Shop Floor-4 (175x35x3) Results

After that, this time we integrated process plan selection with WPPW weighted due date assignment but now jobs are scheduled in random order. Although high improvements are provided with this integration SIRO scheduling deteriorated overall performance back.

As a final step we integrated all of the three functions. Weighted scheduling WATC and weighted due date assignment WPPW are integrated with process plan selection. This level of integration is found the best combination. Here we solved WATC-WPPW(OS,RS,ES,R-ES,GA,R-GA) combinations are tested. We found search techniques useful compared to the ordinary solutions and random search technique was the poorest. At the first shop floor R-ES is found best, at the second shop floor GA is found best and at the third and fourth shop floors R-GA is found as the best solution technique. Generally ES, R-ES, GA, R-GA solutions were superior compared to the RS but they found near solutions. Hybrid searches were found promising solution techniques since random search scans solution space better at the beginning of the iterations. Important thing here is the determination of the percentages of the random search and we applied 10\% random search in this study.

High interrelations of these three functions make us to consider integration. For example, outputs of upstream functions become inputs to downstream functions. Since outputs of process planning are inputs to scheduling, we must prepare better process plans with alternatives. Otherwise shop floor utilization may reduce and there might be unbalanced machine loading. If process planners work separate they may select same machines continuously and may select some other machines very rarely. 
Similarly, if scheduling and due date determination are performed independently then we may lose severely from overall performance. If scheduling is performed separately we may schedule some jobs unnecessarily too early or unreasonably too late and we pay substantially for this in terms of overall penalty function which is the total weighted earliness, tardiness and due date related costs. If due dates are determined alone then we may give unreasonably too close due dates or unnecessarily too late dates. If we give too close dates then we may not keep our promise and pay for loss of goodwill, loose customer and high tardiness. If we give long due dates then we pay for earliness and due date related costs and we may have lost customer or reduce price and no customer wants far due dates.

Briefly, we integrated process plan selection with WATC weighted scheduling and WPPW weighted due date assignment to reduce sum of weighted earliness, tardiness and due date related costs. As an important aspect of this study we give closer due dates for more important customers and schedule these customers earlier to reduce total punishment cost.

According to the results we found full integration level as the best combination and hybrid searches were found promising search techniques. Ordinary solutions are found poorest as expected.

\section{Appendix A: Due-Date Assignment Rules}

WPPW (Weighted Process Plus wait) Due $=\mathrm{qx} *$ $\mathrm{w} 1+\mathrm{w} 2 * \mathrm{kx} * \mathrm{TPT}$ (w1,w2 is determined according to weights) $\mathrm{qx}=\mathrm{q} 1, \mathrm{q} 2$ or $\mathrm{q} 3 \mathrm{q} 1=0.5 * \mathrm{Pav}, \mathrm{q} 2=\mathrm{Pav}$, $\mathrm{q} 3=1.5 * \mathrm{Pav}, \mathrm{kx}=1,2,3$

RDM (Random due assign.)

Due $=\mathrm{N} \sim(3 *$ Pav,$($ Pavg $) 2)$

$\mathrm{TPT}=$ total processing time

Pavg $=$ mean processing time of all job waiting

\section{Appendix B: Dispatching Rules}

WATC (Weighted apparent tardiness cost): This is composite dispatching rule, and it is a hybrid of WMS (Weighted minimum slack) and WSPT (Weighted shortest processing time) rules.

SIRO (Service in Random order): A job among waiting jobs is selected randomly to be processed.

\section{Acknowledgement}

This research is supported by the Sakarya University Scientific Research Projects Commission with the project number "2016-01-02008".

\section{References}

[1] H.-C. Zhang and M. S, "An integrated model of process planning and production scheduling," International Journal of Computer Integrated Manufacturing, vol. 7, pp. 356-364, 1994.

[2] V. Gordon, J. M. Proth, and C. Chu, "A survey of the state-of-the-art of common due date assignment and scheduling research," European Journal of Operational Research, vol. 139, no. 1, pp. 1-25, 2002.

[3] H. I. Demir and H. Taskin, "Integrated Process Planning, Scheduling and Due-Date Assignment," Sakarya University, 2005.

[4] E. Ceven and H. I. Demir, "Benefits of Integrating Due-Date Assignment with Process Planning and Scheduling," Sakarya University, 2007.

[5] H. I. Demir, T. Cakar, M. Ipek, O. Uygun, and M. Sari, "Process Planning and Due-date Assignment with ATC Dispatching where Earliness, Tardiness and Due-dates are Punished," Journal of Industrial and, vol. 3, no. 3, pp. 197-204, 2015.

[6] H. İ. Demir and C. Erden, "Proses planlama ve ağırlıklı teslim tarihi atama ile birlikte ağırlıklı çizelgeleme probleminin bazı saf ve melez metasezgisel yöntemler ile çözümü," Sakarya Üniversitesi Fen Bilimleri Enstitüsü Dergisi Fen Bilimleri Enstitüsü Dergisi, vol. 21, no. 2, pp. 1-1, Apr. 2017.

[7] W. Tan and B. Khoshnevis, "Integration of process planning and scheduling-a review," Journal of Intelligent Manufacturing, vol. 11, pp. 51-63, 2000.

[8] X. Li, L. Gao, C. Zhang, and X. Shao, "A review on integrated process planning and scheduling," International Journal of, vol. 5, pp. 161-180, 2010.

[9] R. K. Phanden, A. Jain, and R. Verma, "Integration of process planning and scheduling: a state-of-theart review," International Journal of Computer Integrated Manufacturing, vol. 24, no. 6, pp. 517534, 2011.

[10] H. Demir and S. D. Wu, "A comparison of several optimization schemes for the integrated process planning and production scheduling problems," Lehigh University, 1996.

[11] B. Khoshnevis and Q. M. Chen, "Integration of Process Planning and Scheduling Functions," Journal of Intelligent Manufacturing, vol. 2, no. 3, pp. 165-175, 1991.

[12] J. Hutchison, K. LEONG, and D. SNYDER, "Scheduling approaches for random job shop flexible manufacturing systems," International Journal of Production Research, vol. 29, no. 5, pp. 1053-1067, 1991.

[13] Q. Chen and B. Khoshnevis, "Scheduling with flexible process plans," Production Planning \& Control : The Management of Operations, vol. 4, no. 4, pp. 333-343, 1993.

[14] P. Brandimarte, "Exploiting process plan flexibility 
in production scheduling: A multi-objective approach," European Journal of Operational Research, vol. 114, no. 1, pp. 59-71, 1999.

[15] K. H. Kim and P. J. Egbelu, "Scheduling in a production environment with multiple process plans per job," International Journal of Production Research, vol. 37, no. 12, pp. 2725-2753, 1999.

[16] N. Morad and A. Zalzala, "Genetic algorithms in integrated process planning and scheduling," Journal of Intelligent Manufacturing, vol. 10, no. 2, pp. 169-179, 1999.

[17] Y. K. Kim, K. Park, and J. Ko, "A symbiotic evolutionary algorithm for the integration of process planning and job shop scheduling," Computers \& Operations Research, vol. 30, no. 8, pp. 1151-1171, 2003.

[18] J. M. Usher, "Evaluating the impact of alternative plans on manufacturing performance," Computers \& Industrial Engineering, vol. 45, no. 4, pp. 585-596, 2003.

[19] M. K. Lim and D. Z. Zhang, "An integrated agentbased approach for responsive control of manufacturing resources," Computers and Industrial Engineering, vol. 46, no. 2, pp. 221-232, 2004.

[20] W. Tan and B. Khoshnevis, "A linearized polynomial mixed integer programming model for the integration of process planning and scheduling," Journal of Intelligent Manufacturing, vol. 15, no. 5, pp. 593-605, 2004.

[21] M. Kumar and S. Rajotia, "Integration of scheduling with computer aided process planning," Journal of Materials Processing Technology, vol. 138, no. 1-3, pp. 297-300, 2003.

[22] C. Moon, Y. H. Lee, C. S. Jeong, and Y. Yun, "Integrated process planning and scheduling in a supply chain," Computers \& Industrial Engineering, vol. 54, no. 4, pp. 1048-1061, 2008.

[23] C. W. Leung, T. N. Wong, K. L. Mak, and R. Y. K. Fung, "Integrated process planning and scheduling by an agent-based ant colony optimization," Computers and Industrial Engineering, vol. 59, no. 1, pp. 166-180, 2010.

[24] S. Panwalkar and M. Smith, "Common due date assignment to minimize total penalty for the one machine scheduling problem," Operations research, vol. 30, pp. 391-399, 1982.

[25] V. Gordon and W. Kubiak, "Single machine scheduling with release and due date assignment to minimize the weighted number of late jobs," Information Processing Letters, vol. 68, no. 3, pp. 153-159, 1998.

[26] D. Biskup and H. Jahnke, "Common due date assignment for scheduling on a single machine with jointly reducible processing times," International Journal of Production Economics, vol. 69, no. 3, pp. 317-322, 2001.

[27] T. C. E. Cheng, Z. L. Chen, and N. V. Shakhlevich, "Common due date assignment and scheduling with ready times," Computers and Operations Research, vol. 29, no. 14, pp. 1957-1967, 2002.

[28] J. A. Ventura and S. Radhakrishnan, "Single machine scheduling with symetric earliness and tardiness penalties," European Journal of Operational Research, vol. 144, pp. 598-612, 2003.

[29] T. C. E. Cheng, C. T. Ng, J. J. Yuan, and Z. H. Liu, "Single machine scheduling to minimize total weighted tardiness," European Journal of Operational Research, vol. 165, no. 2, pp. 423-443, 2005.

[30] J. B. Wang, "Single machine scheduling with common due date and controllable processing times," Applied Mathematics and Computation, vol. 174, no. 2, pp. 1245-1254, 2006.

[31] S. W. Lin, S. Y. Chou, and K. C. Ying, "A sequential exchange approach for minimizing earlinesstardiness penalties of single-machine scheduling with a common due date," European Journal of Operational Research, vol. 177, no. 2, pp. 12941301, 2006.

[32] Y. Xia, B. Chen, and J. Yue, "Job sequencing and due date assignment in a single machine shop with uncertain processing times," European Journal of Operational Research, vol. 184, no. 1, pp. 63-75, 2008.

[33] V. S. Gordon and V. A. Strusevich, "Single machine scheduling and due date assignment with positionally dependent processing times," European Journal of Operational Research, vol. 198, no. 1, pp. 57-62, 2009.

[34] X. Li, L. Gao, C. Zhang, and X. Shao, "A review on integrated process planning and scheduling," International Journal of, vol. 5, no. 2, pp. 161-180, 2010.

[35] G. I. Adamopoulos and C. P. Pappis, "Scheduling under a common due-data on parallel unrelated machines," European Journal of Operational Research, vol. 105, no. 3, pp. 494-501, 1998.

[36] T. C. E. Cheng and M. Y. Kovalyov, "Complexity of parallel machine scheduling with processingplus-wait due dates to minimize maximum absolute lateness," European Journal of Operational Research, vol. 114, no. 2, pp. 403-410, 1999.

[37] V. Lauff and F. Werner, "Scheduling with common due date, earliness and tardiness penalties for multimachine problems: A survey," Mathematical and Computer Modelling, vol. 40, no. 5-6, pp. 637655, 2004. 